\title{
A three-component one-pot procedure for the synthesis benzimidazolo- quinazolinone derivatives in the presence of chitosan-supported metal nanocomposite as a green and reusable catalyst
}

\author{
Ali Maleki*, Nakisa Ghamari \\ Department of Chemistry, Iran University of Science \& Technology, Tehran 16846-13114, Iran \\ E-mail: maleki@iust.ac.ir
}

\begin{abstract}
A simple and convenient approach for the synthesis of tetraheterocyclic benzimidazolo[2,3-b]quinazolin-1-ones has been developed via a multicomponent reaction, which involves the condensation of 2-aminobenzimidazole, dimedone and various aldehydes using chitosan-supported metal nanocomposite as a green, reusable and environmentally benign catalyst system. Environmental friendly, recyclability, cost-effectiveness, easy workup and excellent yields are the major attributes of this one-pot procedure.
\end{abstract}

Keywords: Benzimidazolo[2,3-b]quinazolinone, multicomponent reaction, dimedone, biopolymer, nanocomposite, nanoparticles.

\section{Introduction}

Multicomponent reactions (MCRs), an important subclass of tandem reactions, are onepot processes in which three or more accessible components react to form a single product that incorporates essentially most or allatoms of the reactants used [1]. One-pot multicomponent strategies grant remarkable advantages over conventional bimolecular 
reactions owing to their convergence, atom-economy, operational simplicity, structural diversity and shortness of the synthetic pathway [2]. MCRs have recently gained a new dimension in the field of designing methods to produce elaborate libraries of biologically active compounds [3]. The fusion of biodynamic heterosystems has emerged as a useful tool for the design of new molecular frameworks for potential drugs with diverse pharmacological activities [4].

Quinazolines are very interesting heterocycles [5] as they serve as building blocks in numerous natural and syntheticproducts that exhibit a wide spectrum of biological and pharmacological activities.benzimidazoloquinazolines have also been an important class of heterocycles in drug research, as they incorporate both biodynamic heterosystems benzimidazole and quinazoline which have shown significant anticancer activities [6]. Additionally, benzimidazoquinazolines have also been identified as cyclin-dependent kinase (CDK) and glycogen syntheses kinase-3 (GSK-3) inhibitors [7].

In view of the importance of these polyheterocyclic compounds, several methods have been quoted in the literature [8-12]. However, these methods suffer from drawbacks such as prolonged reaction time, use of volatile organicsolvents, harmful catalysts, low yields and harsh reactionconditions. Therefore, the search of improved catalysts for the synthesis of benzimidazoloquinazolinone derivatives using an eco-friendly approach is of prime importance. Development of efficient and practical catalysts for organicsynthesis is of considerable interest to both academiaand industries [13].

In recent years, a tremendous upsurge ofinterest has been observed in carrying out various chemicaltransformations under heterogeneous conditions owing tosimplicity in operation, remarkable recyclability andeco-friendly nature [14-16]. In this regard, chitosansupported metal nanocomposite possesses unique features such as environmental 
compatibility, non-toxicity, reusability, non-corrosivity, chemical and physical stability and can be used over a prolonged duration of time.

As a part of our continuing efforts in laboratory towards the development of clean and environmentally benign methodologies for organic reactions [17], herein, we decided to use chitosan-supported metal (ferrite) nanocomposite for the mild and highly efficient threecomponent synthesis of benzimidazolo[2,3-b]quinazolin-1-one derivatives 4 via a multicomponent reaction starting from 2-aminobenzimidazole 1, various aldehydes 2 and dimedone 3 (Scheme 1).

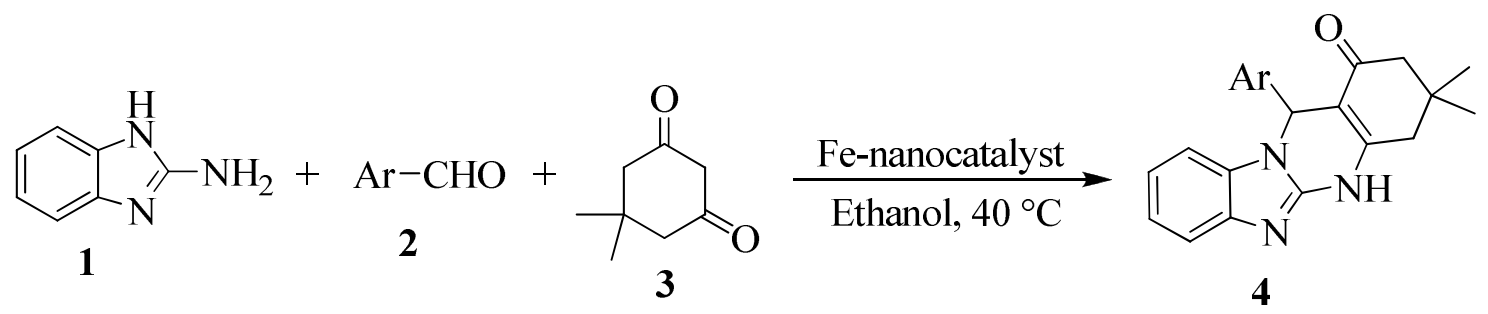

Scheme 1. Synthesis of benzimidazolo[2,3-b]quinazolinones.

\section{Experimental}

\section{Materials and methods}

All chemicals were purchased from Merck, Fluka and Sigma-Aldrich companies and were used without further purification. All reactions and the purity of imidazole derivaties were monitored by thin-layer chromatography (TLC) using aluminum plates coated with silica gel F254 plates (Merck) using ethyl acetate and $n$-hexane as eluents. The spots were detected either under UV light or by placing in an iodine chamber. Melting points were determined in open capillaries using an Electrothermal 9100 instrument. IR spectra were recorded on a Shimadzu FT-IR400s. ${ }^{1}$ H NMR spectra were recorded on an Avance Bruker DRX-300 MHz. 
General procedure for the synthesis of benzotimidazolo [2,3-b]-quinazolin-1-one derivatives

A $10 \mathrm{~mL}$ round-bottom flask was filled with 2-aminobenzimidazole 1 (1 mmol), aldehyde 2 (1 mmol), dimedone 3 (1 mmol) and ferrite/chitosan nanocatalyst (20 $\mathrm{mg})$. The reaction mixture was then stirred at $40{ }^{\circ} \mathrm{C}$ until the reaction was completed. The progress of the reaction was monitored by TLC. Upon completion of the reaction, the catalyst was removed so simple then washed with aceton and after drying could be ready to use for the next reaction without loss in activity. The precipitated were separated by filtration and washed thoroughly with ethylacetat to afford the product. If necessary, simple recrystallization was carried out in $\mathrm{EtOH} / \mathrm{H}_{2} \mathrm{O}$.

\section{Spectral data}

3,3-Dimethyl-12(4-Hydroxy-phenyl)-1,2,3,4,5,12-hexahydrobenzo[4,5]imidazo[2,1-

b] quinazolin-1-one (4c): White powder; $\mathrm{Mp}=312-314{ }^{\circ} \mathrm{C}$; IR $(\mathrm{KBr}): v_{\max }\left(\mathrm{cm}^{-1}\right)=3448$, 2890, 1641, 1612, 1589,1566; ${ }^{1} \mathrm{H}$ NMR $\left(\right.$ DMSO-d $\left._{6}, 300 \mathrm{MHz}\right): \delta_{\mathrm{H}}(\mathrm{ppm})=0.95(\mathrm{~s}, 3 \mathrm{H}$, $\left.\mathrm{CH}_{3}\right), 1.06\left(\mathrm{~s}, 3 \mathrm{H}, \mathrm{CH}_{3}\right), 2.04$ (d, J = 8.9 Hz, 1H, H-4), 2.24 (d, J = 9.2 Hz, 1H, H-4), 2.502.73 (m, 2H, H-2), 6.19 (s, 1H, H-12), 6.60-7.35 (m, 8H, Ar-H), 9.32 (s, 1H, OH), 11.01 (s, $1 \mathrm{H}, \mathrm{NH})$.

\section{Results and discussions}

In order to achieve the most suitable conditions for the present reaction, we first investigated the model reaction using 1 equiv each of 2-aminobenzimidazole 1, 4chlorobenzaldehyde $\mathbf{2}$ and dimedone $\mathbf{3}$. These were stirred at ambient temperature in ethanol. The reaction did not proceed to completion even after $8 \mathrm{~h}$ with only $40 \%$ of the product $\mathbf{4 h}$ being isolated. In order to improve the yield and optimize the reaction conditions, the same reaction was carried out in the presence of chitosan-supported metal (ferrite) nanocomposite 
as a catalyst under similar conditions. Surprisingly, a significant improvement was observed and the yield of the product $\mathbf{4 h}$ was enhanced to $65 \%$ after stirring the reaction mixture for 3 h. Next, we optimized the catalyst loading for this reaction and we noted that although the product could be formed with low catalyst loading $(10 \mathrm{mg} / \mathrm{mmol}$ of the reactant), the best outcome, in terms of yield and the reaction time, was obtained with $20 \mathrm{mg} / \mathrm{mmol}$ of chitosansupported metal nanocomposite (Table 1).

Table 1. Optimization of the amount of the catalyst. ${ }^{a}$

\begin{tabular}{cccc}
\hline Entry & Catalyst $(\mathrm{mg})$ & Time $(\mathrm{h})$ & Yield $^{\mathrm{b}}(\%)$ \\
\hline 1 & 0 & 8 & 40 \\
2 & 1 & 3 & 65 \\
3 & 2 & 3 & 90 \\
4 & 3 & 3 & 91
\end{tabular}

\footnotetext{
${ }^{\mathrm{a}}$ Reaction conditions: 2-aminobenzimidazole $\mathbf{1}$ (1 mmol), 4-clorobenzaldehyde $\mathbf{2 h}$ (1 mmol), dimedon 3 (1 mmol); catalyst: chitosan-supported ferrite nanocomposite; ethanol (2 mL). ${ }^{\mathrm{b}}$ Isolated yields.
}

We also examined the effect of temperature on this reaction. It was found that the optimum temperature was $40{ }^{\circ} \mathrm{C}$ from the point of view of yield and reaction time. At higher temperatures, no further improvement on yield and reaction time was observed. On the other hand, the reaction did not proceed at room temperature. At $40{ }^{\circ} \mathrm{C}$, the reaction proceeded smoothly and almost complete conversion of the reagent was observed.

The scope and generality of this three-component, one-pot synthesis of benzimidazolo[2,3-b] quinazolin-1-onederivatives are well illustrated with structurally diverse aldehydes and the results are summarized in Table 2 . The reaction proceeded smoothly and 
equally well for electron-withdrawing as well as electron-donating aldehydes to afford the corresponding benzimidazolo[2,3-b]quinazolinones in good to excellent yields.

Table 2. Synthesis of benzimidazolo[2,3-b]quinazolinones. ${ }^{\text {a }}$

\begin{tabular}{|c|c|c|c|c|c|c|}
\hline Entry & Amine & $\overline{\mathrm{Ar}}$ & Product & $\mathrm{Mp}\left({ }^{\circ} \mathrm{C}\right)$ & Time $(\mathrm{h})$ & Yield $(\%)^{b}$ \\
\hline 1 & $\begin{array}{c}\text { 2-Amino- } \\
\text { benzimidazole }\end{array}$ & $\mathrm{C}_{6} \mathrm{H}_{5}$ & $4 a$ & $359-363^{[16]}$ & $1 / 45$ & 82 \\
\hline 2 & $\begin{array}{c}\text { 2-Amino- } \\
\text { benzimidazole }\end{array}$ & $4-\mathrm{Me}-\mathrm{C}_{6} \mathrm{H}_{4}$ & $4 b$ & $348-352^{[11]}$ & 2 & 93 \\
\hline 3 & $\begin{array}{c}\text { 2-Amino- } \\
\text { benzimidazole }\end{array}$ & $4-\mathrm{HO}-\mathrm{C}_{6} \mathrm{H}_{4}$ & $4 c$ & $312-314^{[18]}$ & $2 / 15$ & 95 \\
\hline 4 & $\begin{array}{c}\text { 2-Amino- } \\
\text { benzimidazole }\end{array}$ & $4-\mathrm{MeO}-\mathrm{C}_{6} \mathrm{H}_{4}$ & $4 d$ & $373-376^{[16]}$ & $2 / 45$ & 91 \\
\hline 5 & $\begin{array}{c}\text { 2-Amino- } \\
\text { benzimidazole }\end{array}$ & $\begin{array}{c}4-\left(\mathrm{CH}_{3}\right)_{2} \mathrm{~N}- \\
\mathrm{C}_{6} \mathrm{H}_{4}\end{array}$ & $4 e$ & $304-307^{[18]}$ & $2 / 10$ & 91 \\
\hline 6 & $\begin{array}{l}\text { 2-Amino- } \\
\text { benzimidazole }\end{array}$ & $4-\mathrm{NO}_{2}-\mathrm{C}_{6} \mathrm{H}_{4}$ & $4 f$ & $348-351^{[16]}$ & $1 / 50$ & 86 \\
\hline 7 & $\begin{array}{c}\text { 2-Amino- } \\
\text { benzimidazole }\end{array}$ & 4- $\mathrm{Br}-\mathrm{C}_{6} \mathrm{H}_{4}$ & $4 g$ & $363-366^{[16]}$ & 3 & 82 \\
\hline 8 & $\begin{array}{l}\text { 2-Amino- } \\
\text { benzimidazole }\end{array}$ & $4-\mathrm{Cl}-\mathrm{C}_{6} \mathrm{H}_{4}$ & $4 h$ & $383-386^{[16]}$ & $2 / 30$ & 90 \\
\hline 9 & $\begin{array}{l}\text { 2-Amino- } \\
\text { benzothiazole }\end{array}$ & $\mathrm{C}_{6} \mathrm{H}_{5}$ & $4 \mathbf{i}$ & $202-204^{[19]}$ & $3 / 40$ & 79 \\
\hline 10 & $\begin{array}{c}\text { 2-Amino- } \\
\text { benzothiazole }\end{array}$ & $2-\mathrm{HO}-\mathrm{C}_{6} \mathrm{H}_{4}$ & $4 \mathbf{j}$ & $173-175^{[20]}$ & $3 / 10$ & 85 \\
\hline
\end{tabular}

\footnotetext{
${ }^{a}$ Reaction conditions: 2-aminobenzimidazole or 2-aminobenzothiazole 1 (1 mmol), aldehyde 2 (1 mmol), dimedon 3 (1 mmol); catalyst: nanocatalyst $(20 \mathrm{mg})$; temp: $40{ }^{\circ} \mathrm{C}$; ethanol (2 $\mathrm{mL).}$

${ }^{\mathrm{b}}$ Isolated yields.
} 
We also investigated the recyclability of the catalyst system (Figure 1). The model reaction was carried out under the optimized conditions. After complete conversion of the starting materials, the catalyst was extracted so simple and washed with aceton. Then used as such for subsequent runs (four times) with fresh substrates under the same conditions. The recycled catalyst exhibited excellent recyclability in this reaction as the reaction time and yield remained almost the same.



Figure 1. Recyclability of the catalyst.

\section{Conclusion}

In summary, chitosan-supported ferrite nanocomposite been demonstrated as an efficient and environmentallybenign catalyst for the multicomponent synthesis of benzimidazolo[2,3b]quinazolin-1-ones. This protocol further demonstrates in avoiding hazardous organic solvents andtoxic catalysts, reusability of the catalyst, increasing yields, reducing reaction time, and streamlining high-throughput chemistry. The mildness, experimental convenience and compatibililty are also the key advantages which make this method a superior alternative to the existing protocols.

\section{Acknowledgements}

The authors gratefully acknowledge the partial support from the Research Council of the Iran University of Science and Technology. 


\section{References}

[1] Zhu, J.; Bienaymé, H. Multicomponent Reactions. Wiley-VCH: Weinheim, 2005.

[2] Weber, L. Drug Disc. Today 2002, 7,143.

[3] Orru, R. V. A.; de Greef, M. Synthesis 2003, 10, 1471.

[4] McClenaghan, N. D.; Passalacqu, R.; Loiseau, F.; Campagna, S.; Verheyde, B.; Hameurlaine, A. W. J. Am. Chem. Soc. 2003, 125, 5356.

[5] (a) Witt, A.; Bergman. J. Curr. Org. Chem. 2003, 7, 659; (b) Connolly, D. J.; Cusack, D. O.; Sullivan, T.; Guiry, P. Tetrahedron 2005, 61, 10153; (c) Michael, J. P. Nat. Prod. Rep. 1999, 16, 697; (d) Michael, J. P.; Nat. Prod. Rep. 2002, 19, 742; (e) Michael, J. P. Nat. Prod. Rep. 2003, 20, 476.

[6] Grasso, S.; Micale, N.; Monforte, A. M.; Onforte, P.; Polimeni, S.; Zappala, M. Eur. J. Med. Chem. 2000, 35, 1115.

[7] Testard, A.; Picot, L.; Lozach, O.; Blairvacq, M.; Meijer, L.; Murillo, L.; Piot, J. M.; Thiery, V.; Besson, T. J. Enzym. Inhib. Med. Chem. 2005, 20, 557.

[8] Lipson, V. V.; Desenko, S. M.; Shirobokova, M. G.; Shishkin, O. V.; Orlov, V. D. Chem. Heterocycl. Compd. 2003, 39, 1041.

[9] Heravi, M. M.; Derikvand, F.; Ranjbar, L. Synth. Commun. 2010, 40, 677.

[10] Kumari, K.; Raghuvanshi, D. S.; Sing, K. N. Org. Prep. Proced. Int. 2012, 44, 460.

[11] Heravi, M. M.; Ranjbar, L.; Derikvand, F.; Alimadadi, B.; Oskooie, H. A.; Bamoharram, F. F. Mol. Divers. 2008, 12, 181.

[12] Sheldon, R.; Arends, L.; Anefeld, U. Green Chemistry and Catalysis. Wiley-VCH: Weinheim, 2007.

[13] Lee, S. H.; Park, D. R.; Kim, H.; Lee, J. H.; Jung, J. C.; Woo, S. Y.; Song, W. S.; Kwon, M. S.; Song, I. K. Catal. Commun. 2008, 9, 1920. 
[14] Park, S.; Cho, K. M.; Youn, M. H.; Seo, J. G.; Baeck, S. H.; Kim, T. J.; Chung, Y. M. Catal. Lett. 2008, 122, 349.

[15] Song, I. K.; Lee, W. Y. Appl. Catal. A: Gen. 2003, $256,77$.

[16] Insuasty, B.; Salcedo, A.; Quiroga, J.; Abonia, R.; Nogueras, M.; Cobo, Justo.; Salido, S. Heterocycl.Commun. 2004, 10, 399.

[17] (a) Maleki, A. Tetrahedron 2012, 68, 7827; (b) Maleki, A. Tetrahedron Lett. 2013, 54, 2055.

[18] Liqiang, W.; Fulin, F.; Chunguang, Y. Chem. Soc. Ethiop. 2010, 24, 417.

[19] Nagarapu, L.; Gaikwad, H.; Palem, J.; Venkatesh, R.; Bantu, R.; Sridhar. B. Synth. Commun. 2013, 43, 93.

[20] Mazaahir, K.; Ritika, C.; Divya, B.; Mazaahir, K.; Mazaahir, K. Sci. Chin. Chem. 2012, 55, 2154. 